\title{
WHEN OBESE PEOPLE ARE MORE PATIENT THAN NON-OBESE PEOPLE A study of post-surgery individuals in a weight loss association
}

\section{CUANDO LAS PERSONAS OBESAS SON MÁS PACIENTES QUE LAS PERSONAS NO OBESAS}

Un estudio post-quirúrgico de individuos en una asociación de pérdida de peso

\author{
SANTIAGo BudríA sbudria@uma.pt \\ University of Madeira. Portugal \\ JuAn A. LACOMBa jlacomba@ugr.es \\ Granada Lab Of Behavioral Economics (GLOBE). Universidad de Granada. Spain \\ Francisco Lagos fmlagos@ugr.es \\ Granada Lab Of Behavioral Economics (GLOBE). Universidad de Granada. Spain \\ Pablo Swedberg swedberg@slu.edu \\ Department of Business and Social Sciences. St. Louis University. USA
}

\begin{abstract}
The main goal of this article is to investigate the rates of delay discounting among obese people treated surgically and belonging to an association of those interested in controlling their weight. We also analyze whether socio-economic status and personality traits explain the existing differences. Rates of delay discounting are elicited using real monetary incentives in an economic experiment where subjects are asked to make several choices between a smaller, more immediate reward and larger, more delayed rewards. Personality traits are examined using the Five Factor Model. Interestingly, our results show that obese people display lower discount rates than the reference group. These differences can not be explained by personality traits. We argue that obese people do not have to show larger discount rates. In fact, awareness and commitment, rather than their current Body Mass Index, seem to play a more important role in determining this parameter.
\end{abstract}

\section{KEYWORDS}

Delay discounting; Experimental and Behavioral Economics; Obesity. 


\section{RESUMEN}

El objetivo principal de este artículo es investigar las tasas de descuento temporal entre los individuos obesos tratados quirúrgicamente y que pertenecen a una asociación de personas interesadas en controlar su peso. También se analiza si el nivel socio-económico y los rasgos de la personalidad explican las diferencias existentes. Las tasas de descuento diferido se obtuvieron utilizando los incentivos monetarios reales en un experimento económico donde a los sujetos se les pide elegir entre una menor y más inmediata recompensa 0 una recompensa mayor diferida. Los rasgos de personalidad son examinados usando el modelo de cinco factores. Curiosamente, nuestros resultados muestran que las personas obesas muestran tasa de descuento menores al grupo de referencia. Estas diferencias no pueden explicarse por los rasgos de personalidad. Nosotros sostenemos que la gente obesa no debería mostrar mayores tasas de descuento. De hecho, la conciencia y el compromiso, en lugar de su actual índice de masa corporal, parecen desempeñar un papel más importante en la determinación de este parámetro.

\section{Palabras Clave}

Descuento temporal; Economía Experimental y del Comportamiento; Obesidad.

\section{INTRODUCTION}

The prevalence of obesity has grown rapidly throughout much of the world; by between $10-40 \%$ in most developed countries over the last decade (World Health Organization, WHO, 2002, 2003; Baskin et al., 2005; Ogden et al., 2006; Wyatt et al., 2006). This observation raises serious health and policy concerns as obesity is a risk factor for numerous health problems and many chronic diseases.

Recent studies show that obesity is a multiply determined condition that is affected by genetics as well as psychological, social, cultural and technological factors (Philipson, 2001; Baldaro et al., 2003; Cutler et al., 2003; Pinaquy et al., 2003; Komlos et al., 2004; Cutler and Glaeser, 2005; Smith et al., 2005; Elfhag and Lundh, 2007). One dimension which has received increased attention in the literature is the way in which intertemporal decision making affects obesity. Health behaviors, including weight control, are investments where foregone current pleasure leads to improvements in future wellbeing. As such, variations in health behaviors will be explained by differences in discount rates. Obese people are presumably so because they tend to prefer smaller, immediate rewards over larger, future rewards.

The empirical evidence gives support to this hypothesis. Most studies report a positive relationship between body mass index (BMI) and the preference for immediate gratifications (Komlos et al., 2004; Smith, et al., 2005; Borghans and Golsteyn, 2006; Zhang and Rashad, 2008). Other studies, however, report less conclusive results. Nederkoorn et al. (2006) find no group differences in a study that compared obese and non-obese women in a delay discounting task. Controlling for variables of $I Q$ and income, Weller et al. (2008) find that in a delay discounting (DD) of money task, obese women showed greater delay discounting than control women, but obese and healthy-weight men did not differ significantly. Cutler and Glaeser (2005) argue that little of the variation in health 
behaviors, including obesity, can be explained by variations in time preference and is instead largely due to variations in genetics and situational influences.

These discrepancies suggest that further research is needed to shed light on the potential link between BMI and DD. The current research presents a novel feature in this literature: we use a DD task which is not based on hypothetical monetary choices but on real monetary choices. As Frederick et al. (2002) state, the disadvantage of hypothetical choice data is the uncertainty about whether people are motivated to accurately predict what they would do if outcomes were real.

A second feature of our analysis is that we do not use self-reported measures of individuals' weight as a proxy of obesity. Our subject pool is formed of obese people with a medical diagnosis of obesity. This choice is aimed to reduce the measurement error associated with self-reported data that is present in survey-based studies.

Thirdly, we focus on obese individuals who are aware of their status and effectively committed to reduce their weight. Recent research by Rydén et al. (2004) and Sullivan et al. (2007) reports substantial differences in the personality profile of obese individuals depending on whether or not they are committed to weight control. Although they do not consider intertemporal choices, the results give preliminary support to the intuition that obese individuals may differ as well in terms of DD depending on their degree of commitment. Combating obesity implies costs in the short term and benefits in the long term. It is likely therefore that a majority of obese individual with high DD rates coexist with a minority of obese individuals who are aware of their problem and have a preference for delayed rewards over immediate gratifications. In this paper we hypothesize that obese people showing awareness and commitment will not show greater delay discounting than non-obese individuals. To test this hypothesis, we focus on a small subsample of obese individuals. Specifically, our pool of obese people is composed of members of an association dedicated to helping obese people keep their weight under control who, moreover, have been treated surgically for morbid obesity. We interpret these two ingredients as signals of awareness and commitment.

\section{Methods \\ Participants}

The obese people of our subject pool are individuals with a medical diagnosis of obesity. They were contacted through the Association for Obese People (ASOFE) in Almería, Spain. This association brings together individuals who suffer from obesity, have undergone surgery to alleviate this disease and care about controlling their weight. Individuals in this association are obliged to attend nutrition courses that take place on a regular basis in the association, to participate in community discussion and to report their evolution and personal experiences on obesity-related problems. 
Our experiment was conducted at the ASOFE headquarters. On this day, subjects gathered at the association to take part in a course on nutrition and were offered the possibility of participating in our experiment. In the weeks running up to the experiment, the members of ASOFE had been advised to come along in the company of a family member. The participants in our experiment were recruited from two groups. The first group was composed of obese subjects ( $\mathrm{N}=26$ ) from ASOFE (treated group). The second group was recruited from the companions (control group). The first criterion for inclusion in the control group was that the subject be a relative of an obese participant. The reason for this was to reduce part of the unobserved heterogeneity related to genetic factors. Second, prior research has shown that demographic factors including age, gender and economic status are related to DD (Green et al., 1994, Reynolds et al., 2006). Therefore, our second criterion consisted in having demographic characteristics similar to the group of obese people. Those eligible for the control group ( $N=15)$ were invited to participate in the discount experiment. This resulted in two roughly homogenous groups in terms of age, gender, education, employment status and marital status.

Table 1 reports summary statistics for the two groups. In the third column we report the $p$-values of the t-test as well as the Kwallis chi-squared test for the equality of mean coefficients across populations. The statistics show no significant differences between obese and non-obese people regarding age, gender, education, employment or marital status.

Table 1.

Mean scores (and SD) on demographic data

\begin{tabular}{lcccc}
\hline \multirow{2}{*}{ Variables } & Control group & Obese & \multicolumn{2}{c}{ Obese vs. Control group } \\
\cline { 4 - 5 } & & & t-test & Kwallis \\
\hline Age & $40.71(10.17)$ & $41.45(12.14)$ & 0.85 & 0.86 \\
Female & $0.57(0.51)$ & $0.70(0.47)$ & 0.46 & 0.45 \\
More than primary & $0.36(0.50)$ & $0.45(0.51)$ & 0.60 & 0.59 \\
education & $0.50(0.51)$ & $0.65(0.49)$ & 0.40 & 0.39 \\
Employed & $0.17(0.26)$ & $0.30(0.47)$ & 0.11 & 0.11 \\
Single & & & & \\
\hline
\end{tabular}

Source: Own data. 


\section{EXPERIMENTAL PROCEDURE}

An adapted version of the Coller and Williams (1999) and Harrison et al. (2002) tests was used to estimate individual discount rates. Subjects were given a fixed array of 20 paired "future income" options and asked to choose one for each decision. Moving down the table, the early payment (Option A) was always 300 euros but the size of the delayed payment (Option B) increased in each subsequent row, ranging from 303 euros (a 2.0\% return) to 469 euros (a 100\% return). In each row, subjects chose between Options A and $B$. The point at which subjects switched from Option A to Option B is the measure of their discount rates. In other words, by observing the payoff (or equivalently, the implied annual rate of return) required to induce the individual to prefer the delayed payment, we obtained an index of impatience. For instance, if in Row 1, a subject prefers an early payment of $300 €$ rather than a delayed payment of $303 €$, then it can be inferred that the subject's discount rate is higher than $2 \%$; otherwise, it can be inferred that the discount rate is $2 \%$ or less. The time interval between the early payment and the delayed payment was six months.

The main feature that distinguishes our elicitation method from previous research in the field is that it is based on real monetary amounts rather than on hypothetical amounts. In this respect we depart from Weller at al. (2008), who use a DD experiment for a money task based on hypothetical rewards to investigate the link between obesity and impatience among men and women. Methodologically, the advantage of our elicitation technique is that participants' choices are incentive compatible (Hertwig and Ortmann, 2001): participants make choices resulting in real payoffs of $x$ or $x+y$, each of which is paid with some probability. The probability of a monetary payoff (as opposed to hypothetical payoffs) encourages participants to exert greater effort in identifying their true preferences. That is, the elicitation technique directly aligns payoffs with preferences, providing an incentive for individuals to truthfully reveal their intertemporal preferences.

The second feature of our elicitation technique is that it does not allow participants to receive the early payoff on the day of the experiment. This choice is intended to prevent participants from preferring the early payment due to lower transaction costs and not due to their rate of impatience. Thus, we set the early payment date at one month after the day of the experiment and the delayed payment date seven months later.

A copy of the payoff table that our experimental subjects received is shown in Table 2. Subjects' payments were calculated privately at the end of the experiment. Similar to Camerer and Ho (1994) or Coller and Williams (1999), research budget constraints dictated that only one person could be paid for the time preference experiment. This person was randomly selected at the end of the experiment. To ensure the credibility of the procedure, the selected subject was given an official certificate from the University of Granada as a guarantee of payment. Apart from the potential earnings that a participant could earn, all subjects received a 10-euro show-up fee for participating in the economic experiment. 
Table 2.

Payoffs table

\begin{tabular}{cccccc}
\hline Decision & $\begin{array}{c}\text { Payoffs } \\
\text { Option A } \\
\text { (in 1 month) }\end{array}$ & $\begin{array}{c}\text { Payoffs } \\
\text { Option B } \\
\text { (in } 7 \text { months) }\end{array}$ & $\begin{array}{c}\text { Annual } \\
\text { Interest } \\
\text { Rate }(\%)\end{array}$ & $\begin{array}{c}\text { Option } \\
\text { Payment }\end{array}$ \\
\hline 1 & $300 €$ & $303 €$ & 2 & A & B \\
2 & $300 €$ & $308 €$ & 5 & A & B \\
3 & $300 €$ & $315 €$ & 10 & A & B \\
4 & $300 €$ & $323 €$ & 15 & A & B \\
5 & $300 €$ & $331 €$ & 20 & A & B \\
6 & $300 €$ & $339 €$ & 25 & A & B \\
7 & $300 €$ & $347 €$ & 30 & A & B \\
8 & $300 €$ & $355 €$ & 35 & A & B \\
9 & $300 €$ & $363 €$ & 40 & A & B \\
10 & $300 €$ & $371 €$ & 45 & A & B \\
11 & $300 €$ & $380 €$ & 50 & A & B \\
12 & $300 €$ & $388 €$ & 55 & A & B \\
13 & $300 €$ & $397 €$ & 60 & A & B \\
14 & $300 €$ & $405 €$ & 65 & A & B \\
15 & $300 €$ & $414 €$ & 70 & A & B \\
16 & $300 €$ & $423 €$ & 75 & A & B \\
17 & $300 €$ & $432 €$ & 80 & A & B \\
18 & $300 €$ & $441 €$ & 85 & A & B \\
19 & $300 €$ & $450 €$ & 90 & A & B \\
20 & $300 €$ & $469 €$ & A & B \\
\hline
\end{tabular}

\section{Five-Factor Model}

We asked participants to complete a personality questionnaire based on the Five Factor Model of personality (FFM). This questionnaire contains 44 items, each of which is rated on a 5 -point scale anchored by 1 (strongly disagree) and 5 (strongly agree). After aggregating across items, this personality inventory provides a score for the five major traits that define human personality across cultures: Neuroticism, the tendency to experience negative emotions such as anxiety and depression; Extraversion, the tendency to be 
sociable, warm, active, assertive, cheerful, and in search of stimulation; Openness to Experience, the tendency to be imaginative, creative, unconventional, emotionally and artistically sensitive; Agreeableness, the dimension of interpersonal relations, characterized by altruism, trust, modesty, and cooperativeness; and Conscientiousness, a tendency to be organized, strong-willed, persistent, reliable, and a follower of rules and ethical principles. Each of these factors is hierarchically defined by specific facets. The choice of the FFM over other related models is due to the fact that the FFM is the most widely-accepted taxonomy of personality traits (Digman, 1990; Costa and McCrae, 1992; John and Srivastava, 1999).

In Table 3 we report the average scores of the five personality dimensions for each sample. The control group scores slightly higher on Extraversion, Agreeableness, Conscientiousness and Openness (3.67, 3.98, 4.10 and 3.64, respectively) than obese people $(3.51,3.94,3.92$ and 3.59). However, the independent t-test shows that these differences are not statistically significant $(p=0.44, p=0.88, p=0.31, p=0.82)$. The Kwallis tests show similar results. Cronbach's alpha statistic of internal consistency for the five dimensions was: Extraversion 0.681, Agreeableness 0.772, Conscientiousness 0.628, Neuroticism 0.660 and Openness $0.723^{1}$.

Table 3.

Mean scores (and SD) on personality factors

\begin{tabular}{lcccc}
\hline \multirow{2}{*}{ Variables } & Control group & Obese & \multicolumn{2}{c}{ Obese vs. Control group } \\
\cline { 4 - 5 } & & & t-test & Kwallis \\
\hline Extraversion & $3.67(0.50)$ & $3.51(0.61)$ & 0.44 & 0.47 \\
Agreeableness & $3.98(0.65)$ & $3.94(0.58)$ & 0.88 & 0.93 \\
Conscientiousness & $4.10(0.48)$ & $3.92(0.54)$ & 0.31 & 0.33 \\
Neuroticism & $2.70(0.60)$ & $2.96(0.63)$ & 0.23 & 0.28 \\
Openness & $3.64(0.46)$ & $3.59(0.71)$ & 0,82 & 0.67 \\
\hline
\end{tabular}

${ }^{1}$ Cronbach's alpha measures how well a set of items measures a single unidimensional latent construct. The closer Cronbach's alpha coefficient is to 1.0, the greater the internal consistency of the items in the scale. Nunnaly (1978) indicates 0.7 to be an acceptable reliability coefficient, but lower thresholds are sometimes used in the literature. Our estimates are therefore towards the lower range of the estimates reported in earlier studies. Two explanations may account for this fact. First, it should be noted that Cronbach's alpha is a function that depends positively on the number of test items and the average inter-correlation among them. The FFM questionnaire based on 44 items distributed among five factors used in this paper is therefore expected to yield estimates of internal consistency that are lower than those obtained with expanded FFM questionnaires used in other papers. The second explanation has to do with the small sample size, as the low number of observations in our sample leads to lower inter-item correlation. 
Figure 1.

Histogram of $\mathrm{R}$ by groups

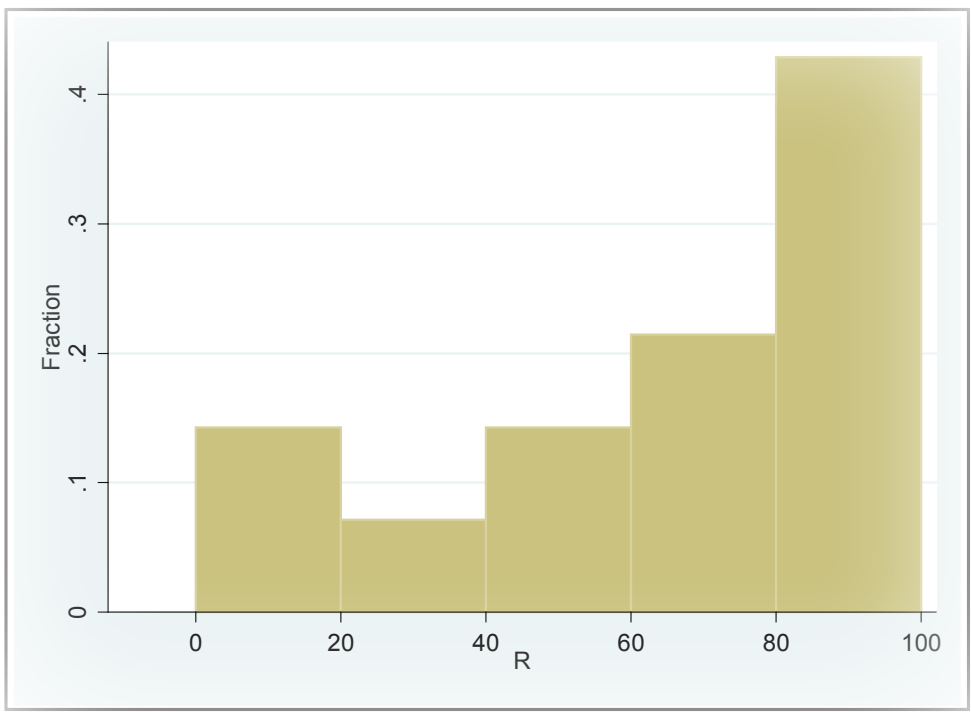

Panel a. Non-obese people ( $36.6 \%$ of the sample). Average discount rate $=66.6 \%$.

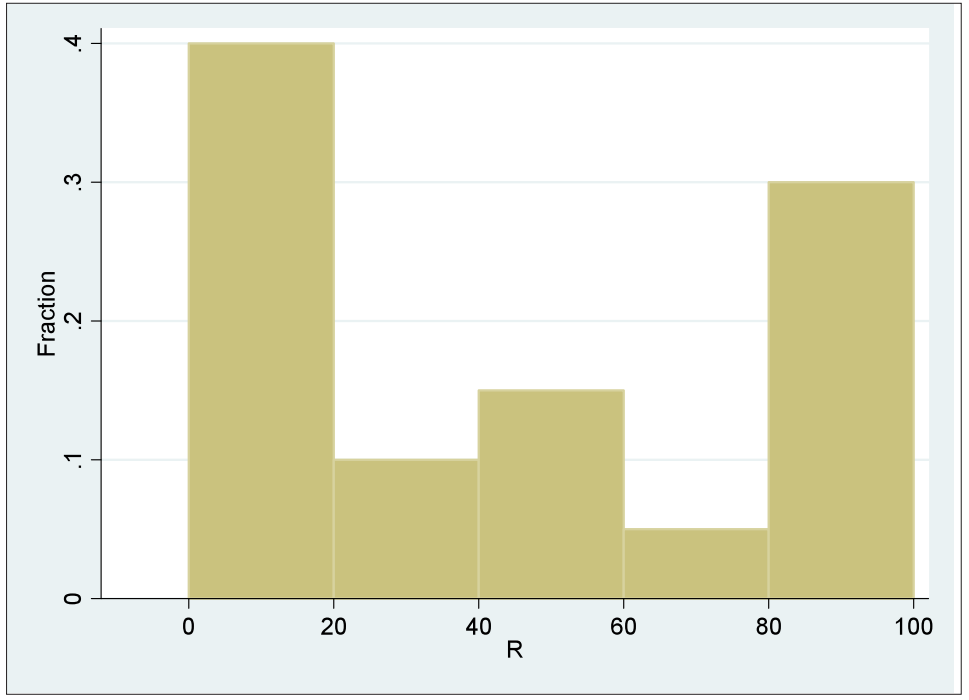

Panel b. Obese people (63.4\% of the sample). Average discount rate $=44.1 \%$. 


\section{Statistical Procedures}

We use multiple regression analysis to examine the relation between $\mathrm{DD}$, obesity, demographic characteristics and aspects of the FFM of personality. Variance decomposition in a set of three alternative specifications and F-tests for the joint equality of coefficients were used to determine which dimensions are more closely related to DD. For all analyses, the statistical software STATA 10.0 for Windows was used.

\section{RESULTS}

\section{Discount rate $(R)$}

The mean DD in this study group was $53.4 \%(S D=40.29) .{ }^{2}$ The $D D$ was lower in the obese group $(44.1 \%, \mathrm{SD}=41.7)$ than in the control group $(66.6 \%, \mathrm{SD}=35.4)$. The differential is significant at the $5 \%$ and $8 \%$ significance level according to the t-test and the Kwallis test, respectively. Bartlett's chi-squared test fails to reject the null hypothesis of equal variances of $R$ in the two samples (chi-squared $=0.394, p=0.530$ ). Accurate inspection of the discount rate $R$ reveals different patterns of responses across obese and nonobese individuals. Figure 1 depicts the histogram of $R$ for both samples, showing that non-obese people tend to be concentrated in the top tail of the discount rate distribution. Specifically, as much as $43 \%$ in this group report $\mathrm{R} \geq 80 \%$. As a result, the corresponding distribution is skewed to the right (panel a). In turn, the fraction of people reporting $\mathrm{R} \geq 80 \%$ is $30 \%$ in the obese sub-sample (panel b). In this case, the histogram reveals that obese people either wait or do not wait, and those with intermediate discount rates account for a relatively low proportion of the sample. Thus, the picture in this group is one of substantial heterogeneity and a bimodal distribution of responses. The largest proportion of obese people is concentrated in the top category of patience $(0-20 \%)$. All in all, this preliminary analysis suggests that obese people are more prone to wait (save) than non-obese people. This statement will be made in a more forceful manner in the next subsection. ${ }^{3}$

\footnotetext{
${ }^{2}$ Our estimates are within the range of estimates reported in the literature. In an excellent survey, Frederick et al. (2002) summarize the implicit discount rates from all studies about discount rates that were either directly reported or easily computed from the reported data and find a tremendous variability in the estimates. In a more recent work, Robles et al. (2009) discuss methodological issues that may account for the observed differences.

${ }^{3}$ Dohmen et al. (2009) use a discount experiment that is very similar to ours to investigate the link between cognitive ability, risk aversion, and impatience. Partitioning the discount rate into a series of evenly distributed intervals with top-coding, they find that the proportion of 'average' discount rates is relatively low, as most individuals are concentrated around the two tails of the discount distribution. Specifically, they report that almost $25 \%$ of the sample is in the top category of the discount distribution, while an additional $8 \%$ is in the lowest tail of the distribution. The proportion of people in the intermediate intervals is lower than $5 \%$. Although we use wider intervals due to small cell-
} 


\section{Regression ANALYSIS AND VARIANCE DECOMPOSITION}

Discount rates are modeled as a function of demographic factors, including obesity, and personality traits. The specification is:

$$
R_{i}=\beta_{0}+\sum_{\mathrm{k}} \beta_{k} x_{k i}+\text { SObese }_{i}+e_{i}
$$

where $R$ is the elicited discount rate, $x_{k} \quad k=1, \ldots, K$ is a vector of explanatory variables and Obese is a dummy variable that takes the value 1 if the individual is an obese person. The results, based on OLS regressions, are reported in Table 4.

We present the results obtained under three different sets of covariates in vector. First, we report the estimates of a model where only the demographic factors (age, gender, education, employment status and marital status) are the explanatory variables. The most relevant finding is the negative link between obesity and the discount rate. The estimated effect is significant at the $5 \%$ level, thus indicating that, ceteris paribus, an obese individual in our sample has a 28.95 point lower discount rate than a non-obese individual. The remaining covariates are not significant at conventional levels, with the exception of age $(p=0.009)$.

As expected, the restricted sample size of our dataset results in estimates that are not statistically significant in most cases. In this scenario, it is convenient to conduct the analysis by groups of variables rather than to focus on the role played by a given covariate. For that purpose, we report the proportion of the total variation of $R$ accounted for by each of the dimensions considered in the present study (obesity, demographics and personality) in the bottom part of Table 4 . In addition to this statistic, we report the $p$-value of a test of joint significance for the variables included in each dimension. In the first model we find that the demographic dimensions account for $13.8 \%$ of the observed variance in discount rates, while obesity accounts for a non-negligible $11.1 \%$. The two dimensions are jointly significant for $\mathrm{DD}$ determination.

In a next step we removed the demographic variables from the estimating equation and used the five personality dimensions as the only regressors. The most important result is that, after controlling for personality traits, the coefficient of obesity is still negative and significant. Moreover, the proportion of the variance accounted for by obesity $(10.7 \%)$ is almost as large as the variation due to personality factors (11.6\%). The estimates, which represent the increase in the discount rate associated with a 1-point increase in a given personality trait, indicate that only one out of the five dimensions turns out to be significant (Extraversion, $\mathrm{p}=0.083$ ). 
Table 4.

Obesity and discount rates

\begin{tabular}{lrrrrrr}
\hline & Coeff. & p-value & Coeff. & p-value & Coeff. & p-value \\
\hline Obese & -28.95 & 0.035 & -27.51 & 0.053 & -34.92 & 0.019 \\
Age & 1.47 & 0.009 & & & 1.54 & 0.038 \\
Female & 8.82 & 0.493 & & & 9.49 & 0.538 \\
More than primary & -1.75 & 0.903 & & & 17.31 & 0.338 \\
education & & & & & & \\
Employed & 10.60 & 0.443 & & & 3.98 & 0.790 \\
Single & 12.41 & 0.475 & & & 8.30 & 0.641 \\
Extraversion & & & -23.03 & 0.083 & -18.40 & 0.245 \\
Agreeableness & & & 9.96 & 0.302 & -1.80 & 0.886 \\
Conscientiousness & & & -4.34 & 0.783 & -9.36 & 0.547 \\
Neuroticism & & & 3.88 & 0.792 & 3.51 & 0.837 \\
Openness & & & 0.69 & 0.957 & -8.38 & 0.544 \\
Constant & -3.98 & 0.073 & 116.32 & 0.084 & 123.58 & 0.130 \\
\hline Share of the total variance & & & & & & \\
accounted for by: & & & & & & \\
\hline Obesity & 0.111 & $(0.035)$ & 0.107 & $(0.053)$ & 0.146 & $(0.019)$ \\
Demographics & 0.138 & $(0.040)$ & & & 0.157 & $(0.091)$ \\
Personality & & & 0.116 & $(0.516)$ & 0.060 & $(0.499)$ \\
R-squared & 0.25 & & 0.20 & & 0.34 & \\
No. of observations & 41 & & 41 & & 41 & \\
\hline
\end{tabular}

Notes to Table 4: i) The p-values are based on heterocedastic-robust standard errors.

Finally, we present a full specification in which the demographic scores as well as the five personality scores have been included to account for the individual discount rate. Again, obesity is negatively related to DD and the estimated coefficient is statistically significant. With the exception of age, none of the demographic or personality dimensions included in the estimating equation is individually significant at conventional levels. However, if we group the variables into categories, we find that when the demographic factors are taken together, they significantly explain individual $D D(p=0.091)$ and are roughly as relevant as obesity in terms of the explained variance (15.7\% versus $14.6 \%)$. In turn, the five personality traits account for only a small proportion of the total variance $(6.0 \%)$ and are not jointly significant. 


\section{Discussion}

This study aimed to provide empirical evidence on the potential links between obesity and intertemporal preferences. Our results showed that obese people concerned about controlling their weight displayed lower rates of delay discounting than individuals in the reference group. The results controlled for other individual characteristics that are potentially relevant for $\mathrm{DD}$, namely demographic factors and personality traits as measured by the FFM. The delay discounting difference between the obese group and the reference group was therefore not related to differences in personality or socioeconomic status.

This is the first study to use real monetary choices rather than hypothetical ones to elicit time preferences in obese individuals. Previous studies that used delay discounting with hypothetical monetary rewards did not find group differences between obese and control adult women (Nederkoorn et al., 2006) or between obese and control adult men (Weller et al., 2008). However, Weller et al. (2008) did find that obese women showed greater delay discounting than control women. The discrepancies between our results and those of the above studies could be related to methodological differences (we use real monetary incentives), or to our particular sample (we study obese people treated surgically who belong to an association aimed at keeping their weight under control).

What can explain the fact that the obese people in our study show lower delay discounting than individuals in the reference group? Why do the obese people in our study behave so differently than in previous studies? A candidate explanation has to do with the interaction between commitment and personality. Psychologists have long investigated the role of time preference and related personality traits (Chapman et al., 2001; Terracciano et al., 2008). A common finding is that specific personality factors are positively related to $\mathrm{DD}$. At the same time, the evidence pointing to significant correlations between obesity and the personality traits related to DD suggests that differences in personality may go a long way towards explaining the incidence of obesity among specific groups. However, recent research by Rydén et al. (2004) and Sullivan et al. (2007) reports substantial differences in the personality profile of obese individuals depending on whether or not they are committed to weight control. Rydén et al. (2004) find that maintained weight reduction was associated with changes in practically all personality traits in proportion to the magnitude of weight loss. These changes implied a convergence towards the population of non-obese individuals. Sullivan et al. (2007) investigate how certain personality traits could contribute to obesity and the response to behaviorally-based weight loss therapy. They find that personality traits differ between obese individuals who enroll and who do not enroll in a comprehensive weight management program. According to this evidence, we should expect that obese people committed to weight control are roughly similar to non-obese people along the different personality traits. This is exactly what we found in Table 2 of the present study. Thus, a candidate explanation for our findings is that obese people committed to weight control are not more impatient than non-obese people because they do not exhibit personality traits that are positively correlated with DD. 
A question that remains to be answered is, however, why obese people in our sample are more patient than the control group. To our eyes, this finding just barely scratches the surface of how and to what extent obese people might differ depending on whether or not they are aware of and committed against their problem. We must note that unlike most other research the obese subject pool of our study is not a random sample, but a selected group of individuals with two distinct characteristics. First, they have undergone surgery to avoid morbid obesity and second, they belong to an association of obese people interested in controlling their weight. These characteristics can be interpreted as distinct signals of awareness and commitment. Frederick et al. (2002) suggest that time preference is tri-dimensional, comprising three separate underlying motives: impulsivity, the tendency to act spontaneously and without planning; compulsivity, the tendency to stick with plans; and inhibition, the ability to override automatic responses to urges or emotions. While most studies point to a positive relation between obesity and impulsivity, our results suggest that compulsivity and inhibition may be more prevalent among obese people who are aware of their status and effectively committed to weight loss. As investments in weight control pay off only in the longer term, these individuals are more concerned about the future than non-obese people. All in all, our results warn that obese people committed to controlling their weight do not have to show larger discount rates. In fact, their commitment, rather than their current BMI, seems to play a more important role in determining their time preference rates.

Moreover, recent research by Shamosh and Gray (forthcoming) and Dohmen et al. (2009) states that with more cognitive resources available, it becomes possible to regulate the initial impulse towards the immediate reward in favor of longer-term goals. Hirsh et al. (2008) find that extraversion predicts higher discounting rates at the low end of the cognitive distribution, while emotional stability predicts lower discounting rates at the high end of the cognitive distribution. These two features suggest that our subjects could have higher emotional stability and/or more cognitive resources available to them, thus reflecting higher strength of self-regulatory control networks and implying lower rates of delay discounting.

Certain limitations should be noted in the present study. The first one is the reduced number of individuals used in the analysis. Our restrictive selection criteria came at the costs of reduced sample size, which leads us to interpret our results cautiously.

Second, the current study focused on monetary discounting rates, and, as Hirsh et al. (2008) suggest, a different pattern of results might be observed when examining the discounting of other reward types (e.g., directly consumable rewards such as food). A larger sample with real and non-monetary delay discounting tasks would allow us to go forward in this research.

Finally, this paper does not consider other dimensions that are potentially relevant for individual DD, among them cognitive ability as mentioned above. It would be interesting to test whether there are systematic differences between the cognitive ability of obese and non-obese people and to investigate whether the results reported in this paper are partially driven by this association. This issue is left open for future research. 


\section{REFERENCES}

Baldaro, B., Rossi, N., Caterina, R., Codispoti, M., Balsamo, A. and Trombini, G., 2003. "Deficit in the discrimination of nonverbal emotions in children with obesity and their mothers." International Journal of Obesity and Related Metabolic Disorders 27:191-195.

Baskin, M. L., Ard, J., Franklin, F., and Allison, D. B., 2005. "Prevalence of obesity in the United States." Obesity Review, 6:5-7.

Borghans, L., and Golsteyn, B. H. H., 2006. "Time discounting and body mass index, evidence from the Netherlands." Economics of Human Biology 4:39-61.

Camerer C. and Ho T., 1994. "Violations of the betweenness axiom and nonlinearity in probability." Journal of Risk and Uncertainty 8: 167-196.

Chapman, G., Brewer, N., Coups, E., Brownlee, S., Leventhal, H., and E. Leventhal. 2001. "Value for the future and preventative health behavior." Journal of Experimental Psychology 7(3): 235-250.

Coller M. and M. B. Williams.1999. "Eliciting Individual discount rates." Experimental Economics 2:107-27.

Costa, Paul T. and R. McCrae. 1992. "Four ways five factors are basic." Personality and Individual Differences 13(6):653-65.

Cutler, D. and E. Glaeser. 2005. "What explains differences in smoking, drinking and other healthrelated behaviors?." Paper Number 2060. Harvard Institute of Economic Research Discussion.

Cutler D., Glaeser E., and J. Shapiro. 2003. "Why have Americans become more obese?" Journal of Economic Perspectives 17(3): 93-118.

Digman, JM. 1990. "Personality structure: Emergence of the five-factor model. Annual Review of Psychology 41: 417-40.

Dohmen, T., Falk, A., Huffman, D. and Sunde, U. 2010. "Are risk aversion and impatience related to cognitive ability?." American Economic Review, 100(3):1238-60.

Elfhag K., and Lundh L-G. 2007. "TAS-20 alexithymia in obesity, and its links to personality Scandinavian." Journal of Psychology 48:391-398.

Frederik S., G. Loewenstein and O'Donoghue T. 2002. "Time discounting and time preferences: A critical review." Journal of Economic Literature 40(2):351-401.

Green, L., Fry, A. F., and Myerson, J. 1994. "Discounting of delayed rewards: A life-span comparison." Psychological Science 5:33-36.

Harrison G.W., Morten L., \& Williams M.B., 2002. "Estimating individual discount rates for Denmark: A field experiment." American Economic Review 92(5):1606-1617.

Hertwig, R., and Ortmann, A., 2001. "Money, lies, and replicability: On the need for empirically grounded experimental practices and interdisciplinary discourse." Behavioral and Brain Sciences 24:433-451. 
Hirsh JB., Morisano D. and Peterson JB. 2008. "Delay discounting: Interactions between personality and cognitive ability." Journal of Research in Personality 42:1646-1650.

John, O.P. and Srivastava S. 1999. "The Big Five Trait Taxonomy: History, Measurement and Theoretical." Pp. 102-38 in Handbook of Personality: Theory and Research, edited by Lawrence A. Pervin and Oliver P. John. New York: The Guilford Press.

Johnson, M. W., and Bickel, W. K. 2002. "Within-subject comparisons of real and hypothetical monetary rewards in delayed discounting." Journal of Experimental Analysis of Behavior 77:129-146.

Komlos J., Smith P. and Bogin B. 2004. "Obesity and the rate of time preference: is there a connection?" Journal of Biosocial Science 36(2):209-219.

Madden, G. J., Begotka, A. M., Raiff, B. R., and Kastern, L. 2003. "Delay discounting of real and hypothetical rewards." Experimental \& Clinical Psychopharmacology 11:139-145.

Nederkoorn, C., Smulders, F., Havermans, R., Roefs, A., and Jansen, A. 2006. "Impulsivity in obese women." Appetite 47:253-256.

Ogden, C. L., Carroll, M. D., Curtin, L. R., McDowell, M. A., Tabak, C. F., and Flegal, K. M. 2006. "Prevalence of overweight and obesity in the United States." The Journal of the American Medical Association 295:1549-1555.

Philipson T., 2001. "The world-wide growth in obesity: an economic research agenda." Health Economics 10(1):1-7.

Pinaquy, S., Chabrol, H., Simon, C., Louvet, J. P. and Barbe, P.. 2003. "Emotional eating, alexithymia, and binge-eating disorder in obese women." Obesity Research 11:195-201.

Reynolds, B., Ortengren, A., Richards, J. B., and De Wit, H. 2006. "Dimensions of impulsive behavior: Personality and behavioral measures." Personality \& Individual Differences 40:305-315.

Rydén, A., Sullivan, M., Torgerson, J.S., Karlsson, J., Lindroos, A-K. and Taft, C. 2004. "A comparative controlled study of personality in severe obesity: a 2-y follow-up after intervention." International Journal of Obesity 28:1485-1493.

Shamosh, N.A.. and Gray, J.R. in press. "Delay discounting and intelligence: A meta-analysis." Intelligence 10.1016 / j.intell. 2007.09.004.

Smith, P.K., Bogin, B., and Bishai, D., 2005. "Are time preference and body mass index associated? Evidence from the National Longitudinal Survey of Youth." Economics and Human Biology 3:259-270.

Sullivan S., Cloninger, C.R., Przybeck, T.R., and Klein, S., 2007. "Personality characteristics in obesity and relationship with successful weight loss." International Journal of Obesity 31:669-674.

Terracciano, A., Löckenhoff, C.E., Crum, R.M., Bienvenu, O.J. and Costa, P.T. Jr. 2008. "Five-Factor Model personality profiles of drug users." BMC Psychiatry 8:22.

Robles, E., Vargas, P.A. and Bejarano, R. 2009. "Within-subject differences in degree of delay discounting as a function of order of presentation of hypothetical cash rewards." Behavioural Processes (81)2:260-263. 
Weller, R.E., Cook III, E., Avsar, K., and Cox, J., 2008. "Obese women show greater delay discounting than healthy-weight women." Appetite 51:563-569.

WHO. 2002. The world health report 2002 - Reducing Risks, Promoting Healthy Life. Geneva: Wito.

WHO. 2003. Diet, Nutrition, and the Prevention of Chronic Diseases. WHO Technical Report 916.

Wyatt, S.B., Winters, K.P. and Dubbert, P.M. 2006. "Overweight and obesity: Prevalence, consequences, and causes of a growing public health problem." American Journal of Medical Science 331:166-174.

Zhang, L. and Rashad, I., 2008. "Obesity and time preference: The health consequences of discounting the future." Journal of Biosocial Sciences 40:97-113.

Santiago Budría earned his PhD in Quantitative Economics from the University of Alicante (2003) and is currently an assistant Professor at the University of Madeira. He is also Coordinator of the CEEApIA, a research centre financed by the Portuguese Fundação a Ciência e a Tecnologia. Santiago Budría has centered his recent research on the study of the determinants of economic inequality and on the social and individual returns to education and training. His current research agenda gravitates around the well-being consequences of deprivation and social exclusion in modern societies and on the extent and directions of social comparisons. He has long expertise in the field of microeconometrics and the usage of national and intentional datasets, including the Spanish EEF, the European ECHP, the German SOEP and the US SCF. He has also participated in several long-duration projects financed by the European Commission, "Education and Wage Inequality" and "The Economic Costs of business Cycles Fluctuations". He is currently part of the research team of three long-duration, competitive projects financed by the Spanish Ministry of Science and Education and the Regional Government of Andalucia.

Juan Antonio Lacomba earned his PhD in Quantitative Economics from the University of Alicante (2003) and is currently an Associate Professor at the University of Granada and is member of GLOBE. Juan Antonio Lacomba has focused his research on the study of comics, the public pension systems and, more recently, on the behavioral and experimental economics. He has published in prestigious journals such as American Economic Review, Economica, Economic Inquiry, Journal of Population Economics or Social Choice and Welfare.

Francisco LAgos earned his PhD in Quantitative Economics from the University of Alicante (2004) and is currently an Associate Professor at the University of Granada and is member of GLOBE. Francisco Lagos has focused his research on the study of the public pension systems and, more recently, on the behavioral and experimental economics. He has published in prestigious journals such as American Economic Review, Economica, Economic Inquiry, Journal of Population Economics or Social Choice and Welfare.

Pablo Swedberg holds a Ph.D. in Economics by Columbia University and is a Professor of Economic Environment at Instituto de Empresa Business School and at St. Louis University (Madrid Campus). His research focuses on Empirical Microeconomics in the areas of Labor Markets, Immigration and Education. During his time at Columbia University, Swedberg taught as an Adjunct Professor at Teacher's College and as part-time Associate Professor at the School of International and Public Affairs (SIPA) to international graduate students from around the globe. Swedberg's current research focuses on the impact of Spanish language proficiency on immigrants' salaries and employment opportunities in Spain.

RECEIVED: 4 May 2011

ACCEPTED: 20 October 2011 